\title{
Connotation definition and System Optimization of Professional Teaching Standards for Vocational Education
}

\author{
Jianhua Shu ${ }^{1, a^{*}}$, Xiangfeng Meng ${ }^{1, b}$ and Jianghua $\mathrm{Fu}^{1, \mathrm{c}}$ \\ ${ }^{1}$ Suzhou Polytechnic Institute of Agriculture, Suzhou, Jiangsu, China, 215008 \\ asjhszny@126.com, b372820571@qq.com, cfujianghua@sina.com
}

Keywords: Higher vocational institution; Specialty; Teaching standard

\begin{abstract}
The article defines the connotation of the teaching standard of Vocational education, and puts forward the main strategies to promote the system of professional teaching standards: to make clear the functional orientation of professional teaching standards, to improve the structure system of professional teaching standards, and to optimize the content and elements of professional teaching standards.
\end{abstract}

\section{Introduction}

Professional teaching standard is the core content of "quality standard" and the source of "quality assurance", which is used to guarantee vocational education, to strengthen the connotation construction and to promote the quality improvement. In November 2012, the Ministry of Education issued the first batch of higher vocational school professional teaching standards, this standard involves 18 major categories of 410 majors [1]. The general office of the Ministry of Education announced in 2014230 "secondary occupation school professional teaching standards (Trial)"[2][3], in 2015 the Ministry of Education issued "the ordinary high school of higher occupation school (College) professional directory" (hereinafter referred to as the "new professional directory") [4]. Recently, the Ministry of education is organizing the development and revision of professional standards in the new professional catalogue [5]. In our country, the construction of professional teaching standards is still a novelty, theoretical study and practical results of the existing few, with the top-level design of congenital deficiency, which has issued a standard of professional teaching standards emerged framework is not standard, and elements are not unified, expressed irregularities and other issues [6]. It is the premise to realize the standardization of the standardization work, and it is important to improve the scientific, normative and operational standards of the standard.

\section{Connotation Definition of Teaching Standard of Vocational Education}

To The construction of professional teaching standards for vocational education is a research work, and the definition of the object of study is the premise of all research work, it stipulates the scientific direction of research and influences the scientific expression of research content, it is an important aspect to measure the scientific level of research work.

Through the relevant policy documents and theoretical results of the inquiry, I found that there is no clear definition of vocational education teaching standards. The Ministry of education, former deputy minister Xin Lu speech at the working conference, occupation education professional development "teaching standards with international standards, China characteristics, is a useful attempt to further enhance the quality of education and occupation of the attraction, to promote the innovation of occupation education reform has important significance" [7]. This is the definition of professional teaching standards from the point of view. Circular of the general office of the Ministry of education on Issuing the catalogue of the first batch of standards for professional teaching (for Trial Implementation) of secondary vocational schools, in the definition of the professional teaching standards are relatively specific: "professional teaching standards is the basic document for professional teaching, is the fundamental basis of clear training objectives and specifications, teaching organization, standardize teaching management, to strengthen the construction of professional development, teaching and 
learning resources, is the main yardstick to assess the quality of education and teaching, and it is also an important reference the employing units selected graduates of secondary occupation school"[2]. This is mainly from the functional positioning of the professional teaching standards for the definition of the concept. All of the above two define the connotation of professional teaching standards, but all of them fail to reveal their essential characteristics. The author has no attempt to make a scientific definition of the concept of professional teaching standards, but tries to clarify the following two aspects through the definition of the concept: what standards does the professional teaching standard refer to in the field? Is the standard of professional teaching a single standard or a standard one?

First, the standard of professional teaching is about the standard of the whole course of professional teaching, or the standard of the implementation of professional teaching? Broadly speaking, professional teaching refers to the whole process including source, process and results, the main source is a professional set up links, process is the implementation of teaching links, the main link is to evaluate quality of education. In a narrow sense, specialized teaching means the link of education and teaching. The 2005 has written proposal to standard occupation education, the professional quality standards at the national level should include the basic conditions and professional education quality evaluation, professional directory of professional competency standards and core curriculum standards, offered professional standards[8]. Here, the source directory of professional standard belongs to the professional teaching, evaluation standard of professional quality of education is the teaching results of standard, basic conditions of professional competency standards and core curriculum standards, professional start-up is professional teaching process standard. In 2015 the Ministry of Education issued a new "Ordinary College of Higher Occupation Education (College) professional directory", also supporting issued the "ordinary high school of Higher Occupation Education (College) table" and "Ordinary College of higher education and professional occupation professional directory (specialist) professional profile" [9] ", and revised the professional settings management methods", these are the source of the norms of professional teaching. Currently system (Amendment) order of professional teaching standards, is a new professional directory as the basis, and apparently no source of professional directory, professional introduction, establishment and management of these professional teaching; in addition, it is understood that the relevant departments are working on professional assessment standards, that is to say the teaching results are not links included in the professional teaching standards. Thus, the professional teaching standard issued by the Ministry of education should be a narrow concept, which is a standard to regulate the implementation of professional education and teaching.

Secondly, should the standard of professional teaching be a single standard or a standard system? In the field of economic activity, our country divides the standard into four grades: National standards, industry standards, local standards and enterprise standards four. In fact, after the release of some professional teaching standards, since there is no delamination level, it is very difficult to make factors and content choices, and has caused a lot of difficulties for the teaching staff at the grass-roots level[10].Before the Ministry of Education officially released some specialized professional teaching standards, Shanghai and Tianjin carried out the first pilot; In recent years, vocational colleges have also strengthened their own professional teaching standards, and on this basis, improve the internal quality assurance system. Obviously, the standards issued by the Ministry of education belong to the national standards, and the standards issued by Shanghai and Tianjin belong to local standards, and the standards formulated and implemented by various vocational schools belong to the school standards. If we want to consider the characteristics of vocational education, we should strengthen the participation of the profession, reflect the characteristics of the industry, and formulate industry standards, In this way, professional teaching standards should include national standards, industry standards, local standards and school standards, including standards.

\section{System Optimization of Teaching Standards for Vocational Education}

Defining the functional orientation of professional teaching standards. As the standard of teaching implementation, professional teaching standards play a key role in the professional quality standards and play an important role in the link between the preceding and the following. In the specific development 
process, professional teaching standards and professional settings to link the relative standard, set the standard in the implementation of professional orientation and requirements, but also with the professional evaluation standard link echoes, and continuous improvement for professional evaluation standard and its own reserved interface.

From the speech of the leadership of the Ministry of education and the spirit of the relevant documents, the functional orientation of the professional teaching standard is mainly four: provide basic norms for professional teaching, provide the basic basis for professional construction, and provide the main benchmark for evaluating the quality of professional education and teaching, and provide an important reference for graduates of social employers. Among them, the key function is to provide basic norms for professional teaching and to provide basic basis for professional construction in two aspects. The research and formulation of professional teaching standards must meet the above-mentioned functional orientation. From the part of the professional teaching standards have been released, due to both of different regions and different schools, with the top-level design and research is not enough, and the choice of the content of elements in determining not very clear, "standard" and "basis" there is a big question, to a certain extent affected the function of. Therefore, the author suggests that, according to the key functions of the above two aspects, the professional teaching standard should be clearly defined, and the structural system of professional teaching standards should be reconstructed on the basis of the above.

Perfect the system structure of professional teaching standard. It is suggested to adopt the general rules of standardization construction in our country, subdivide the specialized teaching standards according to two dimensions of the horizontal structure and the vertical structure, and realize the systematic optimization of the system structure.

From the horizontal point of view, it is suggested that the current standard of professional teaching in higher vocational schools should be adjusted into two parts, namely, professional teaching, national standards and national standards for professional construction; Each part also can according to the different nature, can be divided into technical standards (such as the quality standard of talent - training objectives and specifications), working standard (such as curriculum standard, high school ideological and political theory course construction standard, academic evaluation methods) and management standards (such as professional basic conditions, open textbook construction management measures); According to its importance and legal effect, the above standards can be divided into mandatory standards and recommended standards.

From a vertical point of view, according to its scope of application, the professional teaching standards are divided into four levels: national standards, industry standards, local standards and school standards. The standard of each level should make clear the function orientation, the factor constitution and the subordinate relation, and realize the function complementation through the system optimization, and play their respective role. Specifically, the national standard of professional teaching standards should be the "bottom line" standard, which is the basic norm of vocational education construction and education, and is an important guarantee for the quality of Vocational education. The national standards shall be formulated and promulgated by the Ministry of education and enforced throughout the country. The standard of professional teaching standards is to adapt to the characteristics of vocational education, profession and industry, which is led by the industry department and combined with the professional standards established by the education department.

It is the requirement of vocational education to deepen the integration of production and education, and also to improve the standards of scientific, practical and operational requirements. Most professions of vocational education are closely related to industry. In this sense, industry standards should be the main type of professional standards of Vocational Education in china. The local standard of professional teaching standards is to adapt to different regions of different professional connotation, professional level of education is uneven and set up professional teaching standards. Therefore, the existence value of local standards is mainly to establish higher standards for local specialties, higher than the national standards and industry standards, or to establish further specific specifications for major content differences. The school standard of professional teaching standards is the professional teaching standard formulated by vocational colleges according to the national standards, trade standards and local 
standards, and in combination with their own actual conditions. School standards should be the most perfect and the most specific standards of professional teaching. It is also an important symbol of the school's level of professional education and the characteristics of running a school. There are strict subordination between different standard level to consider, at this stage, China's focus on the construction of professional teaching standards should be put in the construction of national standards and industry standards, local standards in national standards and industry standards developed after the condition need not to need to make decisions. Not yet completed the national standards, industry standards and local standards for professional development, schools can first formulate and implement school standards, to be released after the standard of higher school standards or the implementation of superior standards.

Elements and contents of optimizing professional teaching standards. The unified component is not only the basic requirement of standardization construction, but also the urgent need to promote the orderly connection between secondary vocational school and higher vocational education. Judging from the published standards of professional teaching, The contents include: professional name, admission requirements, basic education, training objectives, occupation scope, personnel specifications, main connection specialty, curriculum structure, curriculum and requirements, teaching schedule, teaching implementation, teaching evaluation, training environment, professional teachers and other 14 essential elements; Higher vocational education includes: professional name, professional code, enrollment targets, length of schooling and education, employment oriented, training objectives and specifications, occupation certificate, curriculum system and core courses of professional education, basic conditions and teaching suggestions, to study professional advice of 10 elements. Since vocational education is a type, secondary vocational school and vocational school are only the same type of different educational levels, and the standard of professional teaching at the same level should be unified as much as possible.

The content selection of professional teaching standards of vocational education is to satisfy the purpose of formulating standards. Two, it is based on national and local educational policies and requirements. Different levels of professional teaching standards are different in purpose and function, and their content should be different. The purpose of making national standards is to make minimum requirements and establish basic standards. As the national standard in the professional teaching standards in the dominant, the mandatory function is not on the choice of the content should be exhaustive, but should focus on key and few suitable requirements, basic norms in general, the content is roughly equivalent to the 2015 edition of "professional directory" after the "professional profile" can be. Industry standards are jointly developed by the industrial sector and the education sector. It should reflect the organic unity of education, technology and professionalism, and is the professional standard of teaching in the true sense. The scope of application of industry standards is also in the whole country. In the determination of factors, the integrity should be emphasized to realize all the functions of the construction of professional teaching standards; In the content selection, we should pay attention to the basic, reflect the relevant policies and requirements of the country, and can adapt to the practice of the vocational schools in different regions and different levels of development. The local standard in the connecting position in the four grades, in the elements should also complete in content, not only according to national standards and industry standards, and the need to reflect the level of professional education and the local characteristics. The school standard is the combination of the actual development and implementation of professional teaching standards, although the subordinate position in the four grade, but the elements must be complete, the content should be based on national standards, industry standards and local standards, and highlights the school level and school characteristics, requirements should not be less than the national standards, industry standards and local standard.

\section{Acknowledgement}

This paper is attributed to the support of Jiangsu Provincial Commission of Agriculture for sponsoring the research project Federation-based Quality Assurance System in Higher Vocational Institutions of Agriculture: Research and Practice (No. JSNZJ201607; Lead: Jianhua Shu), under the category of Research Projects on Educational and Teaching Reform and Development of Vocational Education of 
Agriculture in Jiangsu Province 2016. It is also the interim achievement of Research on the Mechanism of Federation-based Teaching Material Construction for Vocational Education of Agriculture (No. 2016-135-Y-110; Lead: Jianhua Shu), under the project category of Projects of the National Thirteenth Five-year Plan for Vocational Education of Agriculture.

\section{References}

[1] Department of vocational education and adult education of the Ministry of Education, Professional teaching standards for higher vocational schools (for Trial Implementation) (2012\#217), 2012. (In Chinese)

[2] General Office of the Ministry of education, Professional teaching standards for secondary vocational schools (for Trial Implementation) (2014\#11), 2014. (In Chinese)

[3] General Office of the Ministry of education, Notice on the publication of the second batch catalogue "Professional teaching standards for secondary vocational schools (for Trial Implementation)" (2014\#48), 2014. (In Chinese).

[4] Ministry of education, Measures for the establishment and administration of professional institutions of Higher Vocational Education (specialized courses) in Institutions of higher learning (2015\#10), 2015. (In Chinese)

[5] General Office of the Ministry of education, Professional teaching standards for Higher Vocational Schools (2016\#46), 2016. (In Chinese)

[6] J. Lin, The System and Construction of the National Quality Standards for Higher Education, Higher Education of China, 2017, No. 04, pp. 206-209. (In Chinese)

[7] X. Lu, Further improve the teaching standards for vocational education development pilot work, China Education Daily 2013. (In Chinese)

[8] J.H. Shu, Policy recommendations on the formulation of professional standards for Vocational education, Vocational Education Forum, 2005, No.10, pp.6-9. (In Chinese)

[9] Ministry of Education of the People's Republic of China, Professional catalogue and professional introduction of Higher Vocational Education (specialized courses) in Institutions of higher learning, The Open University of China press, 2016. (In Chinese)

[10] Y.Q. Ma, Development of national professional teaching standards in Vocational Education from the perspective of teaching, Vocational Education Forum, 2016, No. 04, pp. 19-23. (In Chinese) 